\title{
Psychoanalysis, science fiction and cyborgianism
}

\author{
James Sey \\ Department of English \\ Vista University \\ Soweto Campus \\ SOWETO
}

\begin{abstract}
Psychoanalysis, science fiction and cyborgianism

Central to this paper is the understanding that much of crucial importance to psychoanalytic thought rests on a conception of the subject as inseparable from a history of the body a history in turn inseparable from the central tenets of Oedipus, in its turn a concept which originates in and is illustrated by literature. The paper will suggest that when recent cultural theorists, drawing on the implications of cybernetics and infoculture theory, contest the psychoanalytic notion of the subject, it is not surprising that they do so in terms of the possibility of an alternative body - a hybrid form of subjectivity between human and machine. Nor, the paper suggests, is it surprising that it should be science fiction, a genre with a long-standing concern with the possibility of such an amalgam, which supplies the key evidence for a post-oedipal theory of this "cyborg" subject. The paper concludes by speculating on the productivity of the conjunction betw'een literature and thinking about the body, inasmuch as this conjunction attempts to establish a new anthropology of the self
\end{abstract}

\section{Ballard's Crash}

Do we see, in the car crash, a sinister portent of a nightmare marriage between sex and technology? Will modern technology provide us with hitherto undreamed-of means for tapping our own psychopathologies? is this harnessing of our innate perversity conceivably of benefit to us? Is there some deviant logic unfolding more powerful than that provided by reason? (Ballard, 1990[1974]:9)

Ballard's questions are all rhetorical and he would answer them in the affirmative. However, his claim in the introduction to his masterpiece of clinically apocalyptic pornography that "the role of Crash is cautionary, a warning against that brutal, erotic and overlit realm that beckons more and more persuasively to us from the margins of the technological landscape" (1990[1974]:9) indicates an ambivalence 
to the psychological impact of technology, one which, more than twenty years on from Ballard's words, seems perhaps less necessary.

Ballard's science fictional writing has largely been concerned with the tangentially science fictional possibilities of what he, along with many of the socalled "New Wave" science fiction writers (John Brunner, Brian Aldiss and Michael Moorcock, for example), calls "inner space"; that is, a psychologicallyinflected form of SF in which the sole interest is the effect on the human psyche of cultural or technological extremity. Ballard, a chief proponent of this variant of SF, is concerned with what is essentially a change in the relation of the subject to its own psychical forces, brought about by changes in the interaction of the subject with technology. His focus on the pathological consequences and possibilities of the human/technology interface plays itself out in the extraordinarily plausible fiction of Crash, a novel which contains few of the generic markers usually associated with SF, except for a central concern with technology.

The novel details the growing obsession of its narrator, "Ballard", with the erotic possibilities of car crashes; particularly the conjunction of the sexuality of human bodies with the functional and decorative geometry of automobile design. The scars and weals produced on the bodies of crash victims by the design details of car interiors, such as gearstick mountings and manufacturer's steering wheel medallions, become in the narrator's mind the eroticized stigmata of a new form of human sexuality. These obsessions find their embodiment in the character of the "hoodlum scientist" Vaughan, who has turned the pursuit of the eroticized crash into a deviant lifestyle; his ultimate goal is to kill himself in a head-on collision between his own car (a Lincoln Continental - a replica of the car in which John F. Kennedy was assassinated) and the limousine containing the actress Elizabeth Taylor. Vaughan's obsessively reiterated rehearsing of this ultimate crash, photographing, filming and planning, as well as the "content" of the crash itself, serve as the nexus of the novel's central concerns with sexuality, psychology and the quintessentially twentieth century technologies of the automobile and the mass media.

Pivotal to the pornographic and intellectual impact of the novel is its revising of the body's erotic possibilities as those are controlled, destroyed and reshaped by automotive technology. The narrator becomes involved with a woman in Vaughan's entourage of acolytes who has been crippled by a crash and wears a heavy spinal brace. The deep weals on her thighs created by the straps of the brace become for him a new sexual organ, an alternative orifice made erotic by its origin in the high-impact conjunction with the car. As he ejaculates into these fleshly channels a reconfigured set of erotic possibilities opens up to him: 
I dreamed of other accidents that might enlarge this repertory of orifices, relating them to more elements of the automobile's engineering, to the evermore complex technologies of the future. What wounds would create the sexual possibilities of the invisible technologies of thermonuclear reaction chambers, white-tiled control rooms, the mysterious scenarios of computer circuitry? ... I visualized ... the wounds upon which erotic fantasies might be erected, the extraordinary sexual acts celebrating the possibilities of unimagined technologies. In these fantasies I was able at last to visualize those deaths and injuries I had always feared. I visualized my wife injured in a high-impact collision, her mouth and face destroyed, and a new and exciting orifice opened in her perineum by the splintering steering column, neither vagina nor rectum, an orifice we could dress with all our deepest affections ... I visualized the body of my own mother, at various stages of her life, injured in a succession of accidents, fitted with orifices of evergreater abstraction and ingenuity, so that my incest with her might become more and more cerebral, allowing me to come to terms at last with her embraces and postures (Ballard, 1990[1974]:138).

This lengthy passage is necessary both to give a sense of the extraordinary technologization of language Ballard achieves in the novel and to indicate, here densely and concisely expressed, the explicit comnection between sexuality and technology which both he and his fictional namesake wish to explore.

Stylistically the usual repertoire of the pornographer is absent, replaced by a clinical detachment which, when used to articulate such manifestly perverse content, produces a profoundly alienating reading experience. That content, particularly of this passage but of the work as a whole, is indeed perverse, and in the specific psychoanalytic sense of that term. That is, we are presented here with the possibility of the body having an alternately-zoned sexuality, with libidinal investment no longer centred on the genitals. It is clear too that the alternative sexualizing of the body is achieved through an exponentially increasing imbrication of sexuality and technology, beginning with the automobile, which acts almost as a template, and ending with "the mysterious scenarios of computer circuitry". The technology of the automobile is the creator of a radically altered sexual body, one which, in this passage, is tied to a specific fantasy structure. Even non-Freudians would recognise the roots of this structure in aggressivity and incest, two of the fundamentally inassimilable underpinnings of the psychic apparatus which modern civilization has had to renounce in order to establish itself.

In Ballard the narrator's fantasy, the physical and sexual identities of his wife are obliterated by the crash, by the automobile - her face and mouth are destroyed, and the other sexual zones of her body are bypassed in favour of the technologically-created perineal orifice. The fantasy recreation of his wife as a 
post-crash object, however, turns out to be simply the prelude to his desire to understand his mother's "embraces and postures", an abstract cerebration, or even perverse working-through, of his incestuous desire for his mother.

\section{Cyborgianism}

\subsection{Cyborg anxiety}

The foregoing seems a neat enough analysis, but such a psychoanalytic reading of the novel's content underspecifies the larger questions raised concerning the imbrication of bodies and technologies. In what follows I undertake a critical review of some of the ways in which these questions are investigated in contemporary cultural theory, and conclude by counterposing to these technophilic theoretical narratives some considerations about the bodytechnology nexus seen from the viewpoint of psychoanalytic theory. Assumed throughout the essay and made explicit in its concluding remarks is the conviction that a psychoanalytic reading brings to the understanding of the body-technology nexus a dimension unavailable to other forms of cultural anthropology; that is, an ontological reading of the effect of technology on sexuality and the unconscious, a reading which SF is well placed to facilitate. In this context the content of particular texts such as Ballard's, though they are important and elegant aesthetic demonstrations of the body-technology nexus, are less important for this argument than the general ontological questions they raise: the concern is not to analyse the specific ways in which technology impinges on human identity (as in the perverse sexuality of the Ballard passage analysed above), but to draw conclusions about the conditions of that identity itself and whether or not it is fundamentally affected by the apparent encroachments of contemporary technologies. Psychoanalysis is thus used metapsychologically and as a methodology, not to seek to produce psychoanalytic readings or results.

The body of recent theory I have mentioned, which I will call cyborgianism by virtue of its pivotal interest in human/machine hybridity, has two theoretical fields in common with Ballard's characters' fantasies in Crash. The first, and predominant one, is the focus on bodily change through technology. This ranges from actual prosthetics, genetic engineering, artificial intelligence and so on, to the possibility of an actual cybernetic organism indistinguishable in any obvious way from a human being. The latter possibility is almost entirely restricted to (science) fictional texts. The second, imbricated field is a theorising of changes in the form of culture itself due to technology. These would refer to the increasing miniaturization and accessibility of communications technology from the walkman to the satellite dish, and the consequent changes in patterns of human interaction (through computer networks, for example). 
Two metaphors might be employed as a kind of shorthand for the theoretical fields of cyborgianism. The first, of course, is that of the cyborg itself, the hybrid form of human and machine, a cybernetic organism.

In SF, the cyborg is the culmination of a thematic lineage at least as old as the genre - that of the robot. The cyborg thus presents the same set of preoccupations, usually dystopian in upshot, about what happens when machines become difficult to distinguish from human beings. The history of the theme, dated (contemporaneously with what is often regarded as the beginning of SF itself) from Mary Shelley's Frankenstein by authorities like Aldiss and Wingrove (1988), reveals a consistent wish to exert control over an artificially produced human simulacrum, whose simulated or manufactured status seems to dramatise the danger of technology - a product of culture - encroaching too far on human identity - itself a precarious balance between nature and culture. Interestingly, and perhaps inevitably, control over the machine in SF usually takes distinctly oedipal forms. This is most clearly seen in Isaac Asimov's famous "Three Laws of Robotics", formulated with the help of editor John Campbell at the beginning of the 1940s. It is now perhaps unnecessary to rehearse them, but the laws are as follows: no robot may allow a human being to come to harm; a robot must obey orders given by human beings, except where such orders conflict with the first law; and a robot must protect its own existence as long as this does not conflict with the first and second laws. The laws indicate that the servility of the human simulacra to their human creators must be ensured, so it is interesting too that most of SF's robot narratives, not only Asimov's, are enabled by the contingent breakdown of robot programming, so that the situation and the narrative can be resolved by the recuperation of human superiority.

The cultural crisis arising from the realisation that a human/machine hybrid might supercede the human itself has been dubbed "cyborg anxiety":

... the cyborg has stood for the radical anxiety of human consciousness about its own embodiment at the moment that embodiment appears most fully contingent. Cyborg anxiety has stood for a panic oscillation between the 'human' element (associated with affections, eros, error, innovations, projects begun in the face of mortality) and the 'machine' element (the desire for long life, health, physical impermeability ..., dependability, and hence the ability to fulfil promises over a long term) (Csicsery-Ronay, 1991:395.)

Rather than only anxiety about identity, however, it should be noted that there are also important differences in the ways in which cyborg identity has been gendered by SF, as in the vampish robot of Fritz Lang's Metropolis (1927), or more latterly the problematizing of gender roles themselves in cyborg enquiry, as in Haraway's well-known Manifesto for (yborgs (1990). Since the argument of 
the present paper is an ontological one per se, the question of gender in cyborgianism must regrettably be left aside for reasons of space, though issues of the sexualization of the body take their place as the underpinning of the psychoanalytic mode of the analysis.

Specifically, I will argue that the prospect of the possible superceding of human identity by machinic or cyborgian identity has produced two conflicting views.

On the one hand SF sees the possibility as essentially dystopian, one which SF writers and filmmakers have responded to (in accordance, perhaps, with an oedipal imperative in the structure of narrative itself) by a reassertion of some measure of intrinsic human worth. The definitive statement of this essentially ambiguous attitude to technology is Asimov's laws, but it has proved to have a stubborn and continuing existence. A neat contemporary example is the payoff line to James Cameron's 1991 cyborg epic, Terminator 2 - Judgment Day. In the film, Arnold Schwarzenegger reprises his somewhat typecast 1984 role as a killer cyborg from the future, but this time he has been reprogrammed to protect the future leader of the human resistance to machine rule, John Connor, and Connor's mother Sarah. During the course of the cyborg's interactions with these humans, but particularly the young John Connor, it becomes more humanly responsive and less robotic, prompting Sarah Connor to muse that the cyborg would make the perfect father for her son, since it would always be there to protect him.

The pseudo-oedipal structure of the human/cyborg interaction is clear here, and what makes it false is a lack of productive conflict between the boy and the cyborg. The boy is father to the cyborgian man, since he is chiefly responsible for the "humanizing" of the robotic killer, but the reverse could not be true, since John Connor has nothing to fear and reject in the cyborg. By the end of the film, when the cyborg "chooses" to sacrifice itself so that the future development of its technology and a consequent human holocaust might be prevented, Sarah Connor muses that "if a machine - a terminator - could learn the value of human life, maybe we can too". The line is a time-honoured sentiment in SF narrative, and is of course fundamentally conservative of the ontological status of humanity in the face of the challenge that technology brings in the figure of the cyborg.

We might recall Ballard's note of caution about approaching the "brutal, erotic realm that beckons to us from the margins of the technological landscape" to conclude that perhaps the predominant note in SF visions of the human/machine interface is gloomy, dystopian and technophobically cautionary. 


\subsection{Cyborg culture}

Yet not all cyborg theorists would concur. The conflicting response to the one just outlined is that the era of the cyborg, our anxiety about the prospect notwithstanding, is upon us, and that it presents us with exciting and potentially liberatory, or at least politically and culturally radical, avenues. Such theorists add to the metaphor of the cyborg body that of a cyborg culture, the second of the two theoretical fields I mentioned earlier. Its metaphor is cyberspace, the term coined by cyberpunk SF writer William Gibson to describe the realm where information resides in its basic electronic state.

One of the most radical polemicists for the cyborgian culture in cyberspace rendered possible by the information age is Jean Baudrillard (1983:129):

this body, our body, often appears simply superfluous, basically useless in its extension, in the multiplicity of its organs, its tissues and functions, since today everything is concentrated in the brain and in genetic codes, which alone sum up the operational definition of being. The countryside, the immense geographic countryside, seems to be a deserted body whose expanse and dimensions appear arbitrary, ... as soon as all events are epitomised in the towns, themselves undergoing reduction to a few miniaturized highlights. And time: what can be said about this immense free time we are left with ... as soon as the instantaneity of communication has miniaturized our exchanges into a succession of instants?

Baudrillard's vision of the information age is thus one of disembodiment, both in terms of the subject and its "real" experience in space and time

The opening assertions of this passage, that the body is "basically useless in its extension", is a contemporary radicalizing of the classic view of technology expressed by Freud in Civilization and Its Discontents that technology is a functional extension of human physicality, an ambivalent way of "perfecting the organs"; that, finally,

man has ... become a kind of prosthetic God. When he puts on all his auxiliary organs he is truly magnificent, but those organs have not grown onto him and they still give him much trouble at times (Freud, 1985:279280).

Baudrillard's argument is thus that, rather than being tools in the service of the body, contemporary technologies augment the space of the body itself, so that the body and the technology become indistinguishable. For Baudrillard - and this is an argument which makes him influential on the "cyberpunk" literary subgenre in $80 \mathrm{~s} \mathrm{SF}$ - this represents the obsolescence of physical agency and its replacement by technological consciousness. The media of our culture have indeed become 
indistinguishable from their messages, and our subjectivity loses the necessity for origin stories because of its instantaneous and internalised electronic mediation.

Thus the subject in contemporary technoculture represents Baudrillard's simulacrum in hyperreality. That subject has what Scott Bukatman (1993), recently termed a "terminal identity" in a pun on the apocalyptic subject experiencing through the screen of computer terminal and TV.

Baudrillard (1983:130) is clear about the kind of subject produced by a culture in the grip of what he calls the "obscene ecstasy of communication":

If hysteria was the pathology of the exacerbated staging of the subject, a pathology of expression, of the body's theatrical and operatic conversion; and if paranoia was the pathology of organization, of the structuration of a rigid and jealous world; then with communication and information, with the immanent promiscuity of all these networks, with their continual connections, we are now in a new form of schizophrenia. No more hysteria, no more projective paranoia, ... but this state of terror proper to the schizophrenic: too great a proximity of everything, the unclean promiscuity of everything which touches, invests and penetrates without resistance, with no halo of private protection, not even his own body, to protect him anymore (132).

The mapping here of hysteric-paranoic-schizophrenic onto the structural topography of theatre-organization-infonnation, although Badrillard does not acknowledge it, bears a strong resemblance to the thesis of Deleuze and Guattari's The Anti-Oedipus: Capiralism and Schizophrenia (1984), which calls for a reconstruing of pathology in order to move beyond the oppressive logic of Oedipus.

Where their argument most nearly touches technological issues in the rather narrow sense in which I have been discussing them is in their two famous revisions of the body in the discourses of psychoanalysis as a "desiring-machine" and as a "Body without Organs" (BwO). What both of these polemically phantasmatic images have in common is a repudiation of Oedipus and zoned sexuality. If the body can be a machine in a circuit of "desiring-production" it escapes the enculturated logic of identification, desire and lack inscribed in the procedures of oedipalization.

Similarly, the $\mathrm{BwO}$ is a metaphor, drawn from more or less pathological discourses such as Artaud's, whose force lies in its presumption of a continually shifting and dispersed cathexis in the body. In this at least the $\mathrm{BwO}$ recalls the technological creation of new bodily oritices in Crash, and allies itself specifically with other aestheticizations of pathology in writers like William Burroughs, and, of course, SF writers like Pynchon and Ballard. 
One further theorist of cyborgianism needs to be considered, since her work is perhaps most representative of contemporary thought on cyborg culture. This is Donna Haraway, whose 1985 (1990) essay A Manifesto for Cyborgs has been very influential. Her central contention (Haraway, 1990:192) is as follows:

... the cyborg is ... the awful apocalyptic telos of the West's escalating domination of abstract individuation, an ultimate self untied at last from all dependency, a man in space. An origin story in the Western humanist sense depends on the myth of original unity, fullness, bliss and terror, represented by the phallic mother from whom all humans must separate, the task of individual development and history, the twin potent myths inscribed most powerfully for us in psychoanalysis and Marxism ... The cyborg skips the step of original unity, of identification with Nature in the Western sense.

What Haraway has in common with other theorists of cyborgianism is the assertion of the revision of subjectivity that a hybrid body brings about, and by extension the revision of the culture to nature relationship which sustains an oedipalized and appropriately zoned human body in its social functions. Haraway thus proposes, perhaps more explicitly than other theorists, a new anthropology of the self.

This entails nothing less than both revising myths of origin and the history of culture in modernity. Like Baudrillard, Deleuze and Guattari, Haraway (ironically it must be said) envisions a new, postoedipal subject. The upshot of her view is that the question of the repressive nature of gender relations will not be changed by a reconfiguration of difference but by an eradication of the question of gender itself in the science fictional figure of the cyborg.

\section{Cyborgs, literature and theory}

Obvious in all the cyborgian critical positions examined here is the twin assertion of a changed subjectivity and a historico-cultural shift. For the cyborgians, contemporary culture is made up of postoedipal or schizoid subjects in a postmodernist world. Just as Freudian metapsychology was seen as an explanatory discourse which underpinned a particular ideology and theory of history (those of capitalism and modernity) and perhaps even helped produce the subject of and in the nomnative nuclear family, so cyborgianism sees itself as the representative theory of a new order of things.

That new order is troped by the cyborg subject, who is untroubled by the apparent or imminent obsolescence of the human being, and rejoices in the transcending of the compromise between culture and nature which the fragile human psyche and the "feeble animal organism" which is its body represent. 
Yet something remains troubling in the heralding of this new order. A symptomatic tension is discernible between the critiques and the goals of cyborgian theory.

The central critique of cyborgianism is against the broadly psychoanalytic account of the physical function of the physical, fleshly body. The major alternatives to this position, as we have seen, are the positing of an ideologically "progressive" schizophrenia or the theoretical possibility of a technologically produced body.

The theorizing of both of these positions depends crucially on literature, usually science fiction, as epistemological evidence. As Baudrillard (1983:128) puts it, as if marking the extremes of his own field of inquiry, "here we are far from the living room and close to science fiction". The use of literature in this way is not of course new, and it seems most significant that the very evidential field which psychoanalysis used in part to corroborate the postulate of the Oedipus complex should be used in much the same way to corroborate the postulate of a postoedipal subject. The important difference is the use to which that "evidence" is put.

While literature in classical psychoanalysis exemplified pathological states or metapsychological tenets, this was useful only insofar as it functioned as an exemplary metaphor, which could then be unpacked in metapsychological or clinical terms. Cyborgian theory, on the other hand, while it uses the figure of the cyborg as just such an exemplary metaphor, wishes also to make of science fiction a self-evident explanation of a subjective or epistemic shift which has already happened, precisely when such literature is by definition about unrealized possibility. In other words, the explanatory force of cyborgian theory must be doubted inasmuch as it makes psychological or anthropological claims for a postoedipal subject which has as yet only a rhetorical or metaphorical existence. The same problems arise for the essentially postmodernist assumption, made by all the cyborgian theorists reviewed here, that political and epistemological claims or analyses can be made using fictional materials as evidence and/or corroboration.

What thus arises in the work of these and lesser, more faddish thinkers, is an utopian confusion of the distinction between an object and its representation(s). Of course, none of these theorists presents an utopian view of the current state of technoculture, but all are utopian in the sense that they look to a future state of more or less progressive postcapitalism and postoedipality. Yet all are compromised by their own discursive mode. As Foucault pointed out (1970), modernity, the "era of the ego", operates through the imperative to confuse an object - the human being - with its representations - language. From within that 
double bind, the empirical-transcendental doublet of modernity, humanity problematizes its own existence. Thus the central question of psychoanalysis, the "counter-science" of modernity, is: how do we know ourselves? The question, thus, which really concerns cyborgianism is: if we create our machines in our image, how are they different from us? The two questions are not so far apart. When cyborgian theorists insist on a posthuman episteme, they do so, as Csiscery-Ronay (1991) points out, as science fiction authors. Which returns us to Ballard.

\section{Conclusion}

Thinking and writing about cyborgs and human subjectivity in contemporary information culture has proliferated enormously in the last few years. Yet few thinkers, if any, have moved forward in any radical way from the positions reviewed in the first part of this essay - they have become more or less representative. What lies at the heart of contemporary thinking about cyborgianism is essentially an unacknowledged, or symptomatic (in the sense of being an unrecognised sign) ambivalence about the status of human beings. "Weak" versions of the cyborgian theoretical conviction that the imbrication of human and machine means the superceding of humanity by a higher order of hybrid cyborg are somewhat naively celebratory of such a prospect. Those versions that are apocalyptic and gloomily millenial, like Baudrillard's, yet revel in the vindication for theory that the prospect of a cyborg culture brings. But behind these manifestations lies the ontological problem of how it is possible to think through one's own death, be it subjective or cultural. The cyborgian positing of a posthuinan culture evades - or rather, elides - both the problem of origin and the problem of being. It is a posthuman postmodernity that is paradoxically but tellingly teleological. To the extent that cyborgian theory can be seen as an example of a projection onto technology of our own ambivalences about our split subjectivity, it has lessons to learn from authors like Ballard who write science fiction as extrapolation rather than theory.

Ballard's intention, thus, is to portray a fictional world where psychopathology is a game which plays out on a technological board, where psychic extremity in the human mind and body is what produces the possibility of technology, an interaction with it, and the imaginative transcendence of its instrumentality. Finally, we must think through the apocalyptic possibilities of that relation before we can safely declare ourselves obsolete, and replaced by cyborgs.

\section{References}

Ballard, J.G. 1990 (1973). Crash. London : Paladin.

Baudrillard, J. 1983. The Ecstasy of Communication. In: Foster, H (ed.) The AntiAesthetic. Seattle : Bay Press. p. 126-134. 
Baudrillard, J. 1983. Simulations. New York : Semiotext(e).

Baudrillard, J. 1991. Simulacra and Science Fiction: Two Essays. Science Fiction Sindies, 55(18):309-313, November.

Bukatman, S. 1993. Terminal ldentity: the Virmal Subject in Posimodern Science Fiction. Durham : Duke University Press.

Csiscery-Ronay, I. 1991. The SF of Theory: Baudrillard and Haraway. Science Fiction Sindies, 55 (18):387-404, November.

Deleuze, G. \& Guattari, F. 1984. The Ami-Oedipus: Capiralism and Schizophremia. New York: Viking Press.

Freud, S. 1984. Beyond the Pleasure Principle. In: Freud, S On Metapsychology. Harmondsworth : Penguin. p. 275-330.

Freud, S. 1985. Civilization and Its Discontents. In: Freud, S. Civilization, Society and Religion. Harmondsworth: Penguin. p. 251-340.

Foucault, M. 1970. The Order of Things. London: Tavistock.

Haraway, D. 1990. A Manifesto for Cyborgs. In: Nicholson, J. (ed.) Femimism Posimodermism. London : Routledge. p. 190-233. 